\title{
Práticas de educação em saúde para a prevenção da cárie dentária: um estudo qualitativo com cirurgiões-dentistas
}

\author{
Laíse Cecote Garcia*; Tânia Harumi Uchida**; João Paulo Guilherme de Lima*; Raquel Sano Suga \\ Terada***; Renata Corrêa Pascotto***; Mitsue Fujimaki*** $^{* *}$
}

* Mestre em Odontologia Integrada, Universidade Estadual de Maringá

** Doutoranda, Programa de Pós-Graduação em Odontologia Integrada, Universidade Estadual de Maringá

*** Professora Associada, Universidade Estadual de Maringá

Recebido em 11/08/2017. Aprovado em 09/01/2018.

\begin{abstract}
RESUMO
O objetivo do trabalho foi identificar a percepção de cirurgiões-dentistas de serviços públicos da Atenção Básica de uma regional de saúde do Paraná, quanto às práticas de educação em saúde para a prevenção da cárie dentária, por meio de uma pesquisa qualitativa. Foram realizadas entrevistas, baseadas em um roteiro semiestruturado. A transcrição das gravações foi realizada de forma manual e o conteúdo categorizado segundo o método da análise de conteúdo proposta por Bardin. Os resultados apontaram que, nesse contexto, os cirurgiões-dentistas realizam práticas de educação em saúde por meio de ações de transmissão de informação, demonstração, motivação, monitoramento e comunicação. Conclui-se que os profissionais pesquisados demonstraram entendimento da importância da motivação e da persistência para um resultado eficaz do processo educativo, porém foi possível perceber diferentes graus de entendimento do processo educativo.
\end{abstract}

Descritores: Educação em Saúde. Odontólogos. Pesquisa Qualitativa.

\section{INTRODUÇÃO}

A cárie dentária é uma doença de grande prevalência em todo o mundo, acometendo entre $60 \%$ e $90 \%$ das crianças em idade escolar e quase a totalidade dos adultos. No Brasil, apesar de uma expressiva redução do índice de dentes cariados, perdidos e obturados (CPO-D) aos doze anos de idade, $53,4 \%$ das crianças de cinco anos tiveram alguma experiência de cárie e, quase todos os idosos perderam a maioria dos dentes ${ }^{1}$. 
Os resultados apresentados pela Pesquisa Nacional de Saúde Bucal de 2010 são alarmantes e apresentam-se aquém das metas preconizadas pela Organização Mundial de Saúde (OMS), cuja meta para 2010 foi de $90 \%$ e, para 2020, 100\% das crianças livres de cárie ${ }^{2}$.

A cárie dentária tem potencial para causar impacto negativo na qualidade de vida dos indivíduos, levando a um prejuízo das atividades diárias pela ocorrência de dor, perda de sono, dificuldade em se alimentar, interferência nas relações sociais e diminuição da autoestima ${ }^{3}$. Defende-se que o elevado custo dos tratamentos dentários poderia ser evitado, bem como a diminuição da prevalência de cárie, por meio de medidas de prevenção e promoção da saúde ${ }^{4}$. Em uma recente revisão sistemática com metassumarização de estudos qualitativos e pesquisas de opinião foram avaliados fatores que conduzem cirurgiões-dentistas (CD) em todo o mundo à realização de medidas preventivas em relação à cárie dentária. Foi verificado que a consciência preventiva do profissional adquirida durante a graduação e pós-graduação, as habilidades de comunicação para a prática da educação em saúde, além do trabalho em equipe e o incentivo financeiro para a priorização da prevenção foram os fatores mais relevantes ${ }^{5}$. Assim, existe a necessidade de organização dos serviços, priorização da prevenção e promoção da saúde, já que os profissionais ainda trabalham dentro do modelo biomédico dominante ${ }^{6}$.

Uma maior compreensão sobre as razões que conduzem os $\mathrm{CD}$ a aplicar medidas preventivas poderia contribuir para a implementação de estratégias de prevenção da cárie dentária, com vistas à diminuição da prevalência das doenças e suas sequelas. As pesquisas têm mostrado que a educação em saúde reflete positivamente na saúde bucal dos indivíduos, sendo efetivo método preventivo ${ }^{7-11}$. Assim, o objetivo deste trabalho foi identificar as percepções dos $\mathrm{CD}$ quanto às práticas de educação em saúde para a prevenção da cárie dentária.

\section{METODOLOGIA}

Trata-se de um estudo de natureza qualitativa, realizado com $18 \mathrm{CD}$ ligados à Atenção Básica dos municípios de uma regional de saúde do Paraná. Para a realização e relato da pesquisa buscou-se seguir as diretrizes dos critérios consolidados para relatos de pesquisa qualitativa (COREQ) $)^{12}$.

A amostra foi composta por conveniência (Snowball) e foram excluídos os sujeitos que trabalhavam há menos de um ano no serviço. Inicialmente foi elaborado um roteiro, composto por tópicos sobre a visão do $\mathrm{CD}$ quanto às práticas de educação em saúde, experiências vivenciadas durante o curso de graduação, relacionamento com a equipe de saúde, suas perspectivas sobre como as ações coletivas influenciariam a prevenção de cárie e se havia recurso financeiro do município para a aquisição de materiais educativos e melhorias da estrutura física

O contato inicial com os profissionais foi realizado por telefone ou e-mail. Os sujeitos foram entrevistados após a assinatura do Termo de Consentimento Livre e Esclarecido. As entrevistas foram conduzidas no local de trabalho dos CD por um único entrevistador, homem, graduado em Odontologia, mestrando em Odontologia Integrada, que recebeu treinamento prévio sobre a temática da pesquisa e semiótica de comunicação, para a adequada condução do trabalho. As entrevistas duraram de 20 a 40 minutos e foram gravadas utilizando equipamento portátil. Novas entrevistas foram sendo feitas até o ponto de saturação dos dados. A transcrição foi realizada manualmente pelo entrevistador e posteriormente revisada por uma pesquisadora com experiência em pesquisa 
qualitativa, que possuía treinamento em transcrição de entrevistas. A confidencialidade dos dados foi resguardada e garantiu-se o anonimato dos entrevistados, que receberam um código para a identificação de sua fala (E01 a E018).

Foram realizadas codificação e análise de conteúdo de $\operatorname{Bardin}^{13}$, por meio das seguintes etapas: pré-análise, exploração do material e tratamento dos resultados com o auxílio do software The Qualitative Data Analysis \& Research Software 7.0 (Atlas.ti ${ }^{\circledR}$ Scientific Software Development, Berlim, Alemanha). Este auxilia na análise qualitativa de dados textuais, na codificação das falas, na organização dos códigos e famílias e facilita o gerenciamento de grande volume de dados qualitativos. Foram prédefinidas quatro categorias de análise, a partir dos objetivos deste estudo, sendo elas: transmissão de informação, demonstração, motivação e comunicação (figura 1).

O processo de análise dos dados se deu por meio da leitura das entrevistas transcritas, à luz do referencial teórico de Paulo Freire. As expressões chave e as ideias centrais, designadas como unidades de registro, identificadas de acordo com o contexto inserido, denominado de unidade de contexto. As unidades de registro foram agrupadas em categorias ou famílias de acordo com o mesmo sentido, sentido equivalente ou em sentido complementar em categorias (ou códigos).

O estudo foi submetido ao Comitê Permanente de Ética em Pesquisa Envolvendo Seres Humanos (COPEP) da Universidade Estadual de Maringá, seguindo as diretrizes e normas regulamentadoras de pesquisas envolvendo seres humanos resolução $n^{\circ}$ 466/2012 do Conselho Nacional de Saúde e aprovado, obtendo o CAAE ${ }^{\circ}$ 0299.0.093.000-11.

\begin{tabular}{|l|c|l|}
\hline Categoria de Dados & Referência & \multicolumn{1}{|c|}{ Definição Constitutiva } \\
\hline $\begin{array}{l}\text { Práticas educativas por } \\
\text { transmissão de informação }\end{array}$ & (Silva et al., 2015) $)^{21}$ & $\begin{array}{l}\text { Ensinar por meio da transmissão de } \\
\text { informação. }\end{array}$ \\
\hline $\begin{array}{l}\text { Práticas educativas por } \\
\text { meio de demonstração de } \\
\text { técnicas de escovação }\end{array}$ & (Garcia et al., 2004) $)^{9}$ & $\begin{array}{l}\text { Ensinar por meio de demonstração de técnicas } \\
\text { de escovação. }\end{array}$ \\
\hline $\begin{array}{l}\text { Processo educativo baseado } \\
\text { na motivação e persistência }\end{array}$ & $\begin{array}{l}\text { (Ferreira et al., }^{10} \\
\text { 2004) }\end{array}$ & $\begin{array}{l}\text { Educar os indivíduos com motivação e } \\
\text { persistência, entendendo o processo como } \\
\text { lento e progressivo. }\end{array}$ \\
\hline $\begin{array}{l}\text { Processo educativo } \\
\text { baseado na comunicação } \\
\text { eficaz com o indivíduo e } \\
\text { comunidade }\end{array}$ & $\begin{array}{l}\text { (Silva et al., 2015) } \\
\text { Educar o indivíduo e comunidade, por meio } \\
\text { de uma interação horizontal, escuta } \\
\text { qualificada e intervenção de acordo com as } \\
\text { necessidades identificadas. }\end{array}$ \\
\hline
\end{tabular}

Figura 1: Organização e definição das categorias de dados (códigos) 


\section{RESULTADOS E DISCUSSÃO}

Do total de $18 \mathrm{CD}$, foram entrevistados 8 homens e 10 mulheres, com idade média de 39 anos. Dados referentes à forma de contratação, formação (graduação), pós-graduação (lato sensu) e atuação profissional estão presentes na tabela 1 .
Observou-se que a maioria dos CD relataram realizar práticas educativas de transmissão de informação e demonstração. $\mathrm{O}$ monitoramento e motivação do paciente foram pontuados diversas vezes e apontados como uma prática importante nas ações de prevenção.

Tabela 1. Características dos sujeitos da pesquisa $(n=18)$

\section{Características}

\section{Sujeitos da Pesquisa (n)}

\section{Forma de Contratação}

Cirurgião-dentista concursado (ESF - 40 horas)

Cirurgião-dentista não concursado (Contratado - 20 horas)

Cirurgião-dentista (40 horas) e Coordenador de Saúde Bucal

Cirurgião-dentista (20 horas) e Coordenador de Saúde Bucal

Formação (graduação)

Instituição pública

Instituição privada

Pós-graduação (lato sensu)

Saúde Pública

Áreas Clínicas

Atuação Profissional

Clínica privada e SUS

Dedicação exclusiva ao SUS

ESF: Estratégia Saúde da Família.

\section{Práticas Educativas por Transmissão de Informação}

A transmissão de informação como prática rotineira no processo de educação em saúde bucal foi relatada pelos profissionais, conforme podemos observar nas falas a seguir:

“[...] Na triagem todos os pacientes passam por uma palestra com a CD ou com a TSB, e dentro dessa palestra há a apresentação de slide com fotos. Na parte preventiva falamos sobre a composição da cárie, origem e a prevenção da doença [...]" (E09).

"[...] Nós fazemos muitas palestras com grupos de hipertensos e diabéticos, palestras para as gestantes, orientando 
como deve ser o procedimento dela quanto a higiene bucal, sobre a importância da saúde bucal tanto para ela quanto para bebê, ou seja, para toda a sua família [...]” (E011).

Para grande parte dos entrevistados, a estratégia da transmissão de informações tem sido a principal atividade de educação realizada. Porém os profissionais que limitaram a transmissão de informação como única ou principal atividade de educação em sua prática de prevenção demonstraram um entendimento restrito do processo educativo. Paulo Freire ${ }^{14}$ afirma que ensinar vai muito além de depositar, transferir ou transmitir conhecimento. Nesse tipo de educação baseado na narrativa, que tem como protagonista apenas o educador - educação bancária - quanto mais se exercita a deposição de informações, menos desenvolve consciência crítica, mais se estimula sua ingenuidade, o que contribui para a formação de seres passivamente adaptados ao mundo em que vivem. Essa falta de criticidade prejudica a inserção do homem como transformador em potencial, como sujeito. É importante encorajar os profissionais a ampliarem essa visão, compreendendo o contexto social, político e ambiental, pois, para que a educação seja efetiva, é necessário ir além de conceitos e recomendações superficiais.

Milori et $a .^{7}{ }^{2}$ avaliaram o comportamento de diferentes programas preventivos de controle de placa bacteriana. $O$ estudo enfatizou a necessidade de combinar estratégias para alcançar resultados satisfatórios e denunciou a inefetividade de tais programas quando são realizadas práticas apoiadas na transmissão de informação apartadas da problematização da saúde bucal. Queluz ${ }^{15}$ também aponta a transmissão de informação como um modelo limitado para programas de educação em saúde. Sinkoç ${ }^{16}$ enfatiza a necessidade de prudência nas abordagens educativas, para que não haja desrespeito aos valores de cada ser, principalmente no que se refere a imposição de conceitos. A transmissão de informações segundo Couto et al. ${ }^{17}$ deve ser realizada por meio de orientações indiretas, de maneira discreta, sem discriminação para que seus resultados sejam expressivos.

A transmissão de informação não apresenta bons resultados, quando isolada, podendo não gerar mudanças de comportamento na população que sejam significativas para o controle de doenças. A utilização deste método como única estratégia de educação em saúde bucal, pode estar relacionada a uma formação acadêmica deficitária, em relação às disciplinas que trabalham o aspecto social e preventivo. $\mathrm{O}$ currículo ainda conserva a influência do Relatório Flexner, que valoriza o mecanicismo, o biologicismo, a assistência individual, tratamentos altamente tecnificados e de enfoque curativo. Por outro lado, mais recentemente, as Diretrizes Nacionais Curriculares intencionaram reformular os currículos de graduação da área da saúde, com vistas à formação de um profissional mais adequado às demandas do Sistema Único de Saúde, com maior compreensão sobre os fatores sociais, comportamentais, culturais e econômicos ${ }^{18}$.

\section{Práticas educativas por meio de demonstração de técnicas de escovação}

Para além da prática de transmissão de informações, os CD demonstraram atribuir importância para as ações de educação em saúde bucal e de atividades preventivas, como a escovação supervisionada, o que pode ser observado nas falas a seguir:

"[...] Mesmo em uma escovação supervisionada, feita em uma escola, é muito diferente você mandar as crianças escovarem e largarem elas lá e vocêfalar e vendo quem está conseguindo fazer, 
quem está fazendo certo, quem está fazendo errado, quem não está conseguindo fazer" (E08).

"[...] eu fico um tempão ali na pia orientando, explicando, é assim, é desse jeito, tem que escovar melhor, esse movimento circular aqui, é menorzinho, uma bolinha menor." (E015).

Entre os entrevistados, a demonstração foi atribuída como uma estratégia educativa importante e que resulta na incorporação de hábitos saudáveis. Auxilia o ganho de habilidades motoras e cognitivas a partir da troca de experiências e informações entre o profissional e o paciente, enriquecendo o momento desta interação. A escovação supervisionada é parte da atividade prática do processo de educação, que possibilita o desenvolvimento de habilidades motoras.

O controle do biofilme por meios mecânicos é considerado um recurso importante para o combate a um importante agente etiológico da cárie e das doenças periodontais. Vários autores afirmam que, para ser eficaz, a escovação deve ser orientada e supervisionada pelo profissional motivando o paciente ${ }^{19-21}$.

Resultados encontrados no estudo de Garcia et al. ${ }^{9}$ corroboram com os achados, pois ao avaliarem um programa de educação sobre o conhecimento e comportamento de higiene bucal, identificaram que os pacientes que receberam instruções de higiene e escovação supervisionada, obtiveram uma mudança comportamental positiva relacionada aos hábitos de higiene bucal. Houve também um aumento no número de pacientes que passaram a escovar e a utilizar o fio dental corretamente e com mais frequência. Kunert et $a l^{22}$, descreveram um programa direcionado aos alunos da Academia de Polícia da Brigada Militar no Rio Grande do Sul, no qual a evidenciação da placa bacteriana, com corante, mostrou-se de grande valia, melhorando a higiene bucal sem utilizar técnicas padronizadas de escovação. A escovação é de fácil aplicabilidade, pois exige poucos recursos, além de ser de fácil execução. Frazão $^{23}$ avaliou a realização da escovação supervisionada e o resultado mostrou um ótimo custo-benefício.

\section{Processo educativo baseado na motivação e persistência}

Foi relatada a importância da repetição nas abordagens educativas, de motivação e do monitoramento dos resultados obtidos, buscando efetividade na construção do conhecimento, que acontece de forma lenta e progressiva e no desenvolvimento de habilidades de higienização, como pode ser constatado nos trechos seguintes:

"O que não funciona, por exemplo, é ensinar uma vez a fazer, e não fazer a repetição, porque mudar o hábito é complicado, não é uma vez ou duas que ele vai mudar [...] Todas as vezes que ele (paciente) voltar tem que fazer evidenciação e tem que fazer escovação supervisionada. Então, não é efetivo fazer uma vez e achar que ele aprendeu, ele pode até aprender, mas não vai conseguir assimilar e não vai conseguir mudar o hábito dele" (E08).

"[...] Para você mudar o pensamento não é com dois anos, [...] tem que fazer um trabalho intenso, com toda a população e por muito tempo [...]" (E02).

"[...] Então, o que eu percebo que não funciona são os trabalhos isolados, você ir uma vez só naquela escola, fazer uma atividade naquele dia e nunca mais aparecer, [...] o que garante o controle da doença, o que dá resultado são as atividades de educação e prevenção, é o tratamento a longo prazo, com continuidade [...]" (E010).

"[...] A prevenção é uma sementinha que você não sabe quando vai brotar [...]" 
(E15).

Ao relatarem que as atividades pontuais não surtem resultados esperados em longo prazo, demonstram o entendimento da educação como um processo lento, tanto em nível individual quanto coletivo. Esta consciência do papel do CD como responsável por planejar, coordenar, implementar e incentivar as atividades de educação em saúde voltadas para a prevenção das doenças bucais, não foram encontradas na maioria das entrevistas.

A educação em saúde bucal é uma ação importante do processo de promoção da saúde, exigindo prática e conhecimento ${ }^{24}$. Surge como um desafio aos $\mathrm{CD}$, considerando a necessidade de substituição de um modelo assistencial curativo, de alto custo e baixo impacto epidemiológico, que ainda é vigente em diversos municípios brasileiros ${ }^{25}$. No entanto, o trabalho de educação em saúde bucal precisa ser ampliado para que a sensibilização alcance todos os grupos sociais. De acordo com Sheiham ${ }^{26}$, tal prática deve ser integrada à educação para a saúde geral, demandando que o CD reconheça o seu papel para além de sua especificidade.

A motivação é um fator necessário para estimular o paciente a modificar seu comportamento, instituindo hábitos suficientes para o controle do biofilme ${ }^{18}$. Os profissionais da saúde devem ser flexíveis na forma de demonstração das práticas educativas. Se forem excedidos os limites de percepção e apropriação, a população poderá reagir de forma negativa ${ }^{10}$. Para isso é necessário dispor de métodos e estratégias de motivação, buscando o reforço das informações, que serão fixadas e incorporadas ao cotidiano por meio da continuidade das ações ${ }^{27}$.

Resultados de um estudo realizado por Garcia et al. ${ }^{9}$ demonstram que após um determinado período de tempo sem monitoramento, existe a tendência de ocorrer um menor rigor acerca da higiene bucal, defendendo que a educação e a motivação devem ser reforçadas periodicamente. Resultado parecido foi encontrado por Ferreira et al. ${ }^{10}$, em um programa educativo desenvolvido em uma Unidade Básica de Saúde, que, ao discutir os tópicos relativos à educação em saúde bucal para adultos, concluíram que a motivação contínua é mais efetiva que a imposição de técnicas padronizadas.

Em um estudo qualitativo realizado com Técnicos em Saúde Bucal, foi demonstrado que o monitoramento e avaliação do paciente são estratégias importantes para analisar o aprendizado e ressaltar a necessidade de reforçar as orientações de higiene bucal previamente instituídas ${ }^{28}$. Dessa forma, o monitoramento do paciente atua como um fator fundamental no processo educativo, necessário para a mudança de hábitos relativos à saúde bucal, além de auxiliar na avaliação do seu nível de entendimento das questões básicas de higiene bucal.

\section{Processo educativo baseado na comunicação eficaz com o indivíduo e a comunidade}

Por fim, a última categoria analisada diz respeito à necessidade de abertura de diálogo com a comunidade, mediante realização de práticas educativas baseadas na comunicação interativa.

“[...] Os grupos se reúnem geralmente em igrejas, em espaços onde não é possivel fazer escovação. São rodas de conversa e eu acho até mais efetivo que palestra, porque elas participam, elas falam das dificuldades delas, então não fica assim uma coisa de cima pra baixo é uma conversa mesmo [...]" (Entrevistado E08).

Apenas um relato evidenciou a abertura do profissional para trocas de experiências e percepções com a comunidade na prática da 
educação em saúde. Essa prática é importante para compreender as experiências de vida de cada indivíduo, assim como seus valores e crenças, potencializando o crescimento individual e do grupo. Esta estratégia pode ser mais efetiva que a transmissão de informação em uma palestra, quando esta não promove uma interação com o público e limita-se à fala de um orador com um conhecimento científico maior.

A dificuldade dos profissionais em experimentar estratégias não habituais e inovar no processo educativo, representa desafios a serem superados na Odontologia. Segundo Cohen et $a l{ }^{29}$, a profissão apresenta limites frente aos problemas de saúde bucal, uma vez que o $\mathrm{CD}$ é treinado em demasia para a realização de tratamentos reparadores e pouco para prevenção, controle da progressão de doença e de manutenção da saúde, defendendo que esses profissionais deveriam ser recompensados por auxiliarem a manutenção da saúde e não por realizarem procedimentos invasivos.

Dentre as distintas formas de se trabalhar a educação, a comunicação se destaca como um processo interpessoal no qual são envolvidas trocas verbais e não-verbais de informações e ideias. A comunicação eficaz não se refere somente ao conteúdo, não é baseada somente em queixas e condutas, mas também aos sentimentos e emoções que as pessoas podem transmitir num relacionamento interpessoal. É considerado um dos mais importantes fatores utilizados para estabelecer um relacionamento de confiança entre profissional-paciente, que irá repercutir na qualidade do cuidado ao paciente ${ }^{30-32}$.

Em consonância com os resultados aqui apresentados, Moimaz et al. ${ }^{33}$, realizaram um estudo com CD da rede pública e particular, demonstrando que a maioria dos profissionais utilizavam satisfatoriamente medidas preventivas, porém, a educação em saúde não estava sendo realizada de maneira sistemática.
Além disso, o tempo destinado a essa atividade foi considerado insuficiente (20 a 25 minutos), impossibilitando uma comunicação eficaz capaz de promover reflexão e resultar em construção de conhecimento e mudança de hábitos.

Segundo Freire $^{14}$ a educação problematizadora rompe com esquemas verticais característicos de uma educação bancária, sendo comprometida com a liberdade, com a criticidade, estimula a criatividade e a reflexão e tem no diálogo a indispensável relação. Nela, a capacidade de aprender supera o autoritarismo e a falsa consciência do mundo.

A comunicação dialógica pode ser empregada como recurso terapêutico para lidar com a insegurança e desconhecimento dos pacientes por meio da interação e vínculo com os profissionais da saúde. Os profissionais desenvolvem habilidades de escutar, observar, perguntar e responder ${ }^{32}$. De acordo com Sousa et $a l .^{34}$, a educação em saúde busca o aperfeiçoamento do cuidado com vistas à saúde e ao bem-estar por meio de um processo dialógico. Quando realizado com grupos coletivos, facilita a conscientização crítica dos indivíduos em suas trocas de experiências, percebem suas limitações e possibilidades no contexto social, favorecendo a organização e concretização de ações de mudança.

A interação dos métodos identificados nas categorias poderia propiciar resultados de maior relevância, como apresentado no estudo realizado por Tomita et al. ${ }^{8}$, foi desenvolvido um programa educativo para escolares adolescentes de diferentes inserções sociais, realizando palestra, evidenciação de biofilme, escovação, atividades educativas dinâmicas com jogos em formato de gincanas, competições e uma oficina pedagógica. Os autores concluíram que programas compostos por diferentes métodos e com atividades participativas têm fundamental importância na mudança de hábitos de higiene 
bucal em adolescentes, independente de sua inserção social.

Para Pauleto et al..$^{35}$ existe um despreparo teórico e prático dos profissionais da Odontologia em relação às medidas de educação em saúde bucal, sendo importante ressaltar a necessidade de uma reestruturação da formação profissional em consonância com as Diretrizes Curriculares Nacionais do Curso de Graduação em Odontologia. Santos et al. $^{36}$ analisaram as percepções de graduandos de um curso de Odontologia sobre o tema "Educação em Saúde Bucal", que consideraram que a participação em atividades de educação em saúde em outros cenários de trabalho trouxe impacto positivo em sua formação e também na vida pessoal, porém os alunos também apresentaram uma visão reducionista do conceito de educação em saúde. Em outro estudo, realizado por Guterman ${ }^{37}$, para a maioria dos pesquisados, $\mathrm{CD}$ e graduandos em Odontologia, a educação em saúde é entendida como prevenção. Os dois trabalhos dizem respeito à formação universitária que necessita de investimentos em relação à ampliação da compreensão da educação em saúde.

Se o entendimento do conceito é limitado, é possível que as ações realizadas por estes profissionais em relação à educação em saúde sejam inadequadas. Além da reestruturação da formação é importante que os profissionais já atuantes, sejam capacitados para adotarem a perspectiva da integralidade da atenção. Existe necessidade de formulação de novas estratégias para capacitação dos trabalhadores, articuladas no contexto dos serviços, visando uma gestão humanizada e qualificada ${ }^{38}$.

Acerca deste tema, o Ministério da Saúde, por meio do Departamento de Gestão de Educação na Saúde, instituiu a Política Nacional de Educação na Saúde, como uma proposta éticopolítico-pedagógica que tem buscado transformar e qualificar a atenção à saúde, os processos formativos, as práticas de educação em saúde e incentivado a organização das ações e dos serviços numa perspectiva intersetorial ${ }^{39}$. Contudo, estudos como os de Silva et al. ${ }^{40} \mathrm{e}$ L'abbate $^{41}$ apontam para uma inadequação nas metodologias empregadas nas capacitações, com necessidade de revisão urgente nas políticas que atente para os momentos, antes, durante e após os cursos, visando a qualificação e o entendimento dos trabalhadores em relação à complexidade do cuidar, com competência e cidadania em direção à integralidade e humanização nos serviços.

A Linha Guia de Saúde Bucal, elaborada pela Secretaria da Saúde do Estado do Paraná, traz como objetivo da educação em saúde, a mudança de comportamento do sujeito, transformando-o em ator ativo do processo saúde-doença, por meio do incentivo e fortalecimento da autonomia dos indivíduos, instrumentando-os para mudança de hábitos e controle da manutenção da sua saúde. O guia menciona o autocuidado apoiado, que vai além de dizer o que cada indivíduo deve ou não fazer, mas reconhecer nessas pessoas sua centralidade na atenção à saúde e desenvolver um sentido de auto responsabilidade sanitária. $\mathrm{O}$ autocuidado apoiado, não tem início e fim em uma aula, é contínuo, com enfoque de cooperação entre os profissionais da saúde e os usuários, para que juntos, definam os problemas, encontrem soluções, estabeleçam metas e elaborem os planos de cuidado e monitoramento dos resultados.

Todas as percepções compartilhadas e vivenciadas pelos sujeitos da pesquisa mostram que as práticas de educação em saúde para a prevenção da cárie ainda se encontram aquém dos pressupostos da Clínica Ampliada (CA). A proposta deste modelo de trabalho visa transpor a clínica tradicional, com foco na doença, para uma atuação além do diagnóstico e tratamento das manifestações clínicas na cavidade bucal. 
Para que a CA possa ser colocada em prática é necessário fortalecer o vínculo com o usuário para entender como ele e sua família vivem, compreendendo o contexto de sua comunidade. Assim, o desenvolvimento da competência em comunicação é necessária, para estabelecer um processo de troca saudável e enriquecedora para ambos. O objetivo é valorizar o autocuidado com o corpo, com a vida, auxiliando-os nas decisões por mudanças viáveis para a incorporação de hábitos mais saudáveis como uma alimentação rica em produtos naturais, atividades físicas regulares, atividades sociais, espirituais e intelectuais ${ }^{42-44}$. É importante que os profissionais que compõem as equipes de saúde trabalhem interprofissionalmente, baseando-se em uma visão ampliada da saúde da comunidade, das famílias e indivíduos que adoecem, contribuindo para a melhora na qualidade de vida das pessoas, não somente interferindo no desconforto e nas sequelas que as doenças apresentam. Dessa forma, verifica-se que no Brasil os CD têm grandes desafios a enfrentar e consequentemente grande responsabilidade pela transformação desta realidade, considerando os altos índices epidemiológicos das doenças bucais. A criação de estratégias para a priorização do controle da cárie dentária, no intuito de diminuir perdas dentárias precoces, é um exemplo que pode ter um impacto muito positivo na vida de crianças, jovens e adultos. Novos processos de trabalho, novos fluxogramas de usuários, novas parcerias intersetoriais e interprofissionais são necessárias para que a clínica possa se ampliar e o aprendizado se tornar coletivo e contínuo para todos os envolvidos.

Apesar dos CD muitas vezes terem dificuldades de encontrar o seu papel no enfrentamento dos determinantes sociais da saúde, que são as "condições nas quais as pessoas nascem, crescem, vivem, trabalham e envelhecem"45, é necessário que pesquisadores, educadores, profissionais e acadêmicos aprimorem o seu olhar e sua atuação para além do processo biológico envolvido, integrando-os com o espaço social que vivem $^{46}$.

\section{CONSIDERAÇÕES FINAIS}

Os CD demonstraram realizar práticas de educação em saúde bucal voltadas à prevenção da cárie dentária por meio de diversas estratégias, demonstraram entendimento sobre a importância da motivação e da persistência para um resultado eficaz e utilizaram métodos interativos para melhorar a comunicação com a comunidade. Contudo, é possível perceber a necessidade de superação do modelo hegemônico limitado à transmissão de informações, sugerindo-se melhor desenvolvimento de habilidades de comunicação na graduação e pós-graduação, além de capacitação dos profissionais nos serviços de saúde.

\section{ABSTRACT \\ Health education practices for the prevention of dental caries: a qualitative study}

The objective of this study was to identify the perception of dental surgeons on public services of Primary Care at Regional Health Service, in Paraná, regarding health education practices for dental caries prevention, through a qualitative research. Interviews were conducted, based on semi-structured script. Recordings transcription was manually performed. The content was categorized according to the Method of Content Analysis proposed by Bardin. The results pointed out that, in this context, dentists perform health education practices through information transmission, demonstration, motivation, monitoring and communication. It is concluded that the studied professionals demonstrated to understand the importance of motivation and persistence for an educational process effective result, however it was possible to perceive different education to process of understanding. 
Descriptors: Health Education. Dentists. Qualitative Research.

\section{REFERÊNCIAS}

1. Brasil. SB Brasil 2010- Pesquisa Nacional de Saúde Bucal. Resultados Principais. Brasília: Departamento de Atenção Básica, Secretaria de Atenção Básica, Ministério da Saúde; 2011.

2. World Health Organization. Oral Health Fact Sheet. n. 318, April 2012. [Acesso em 01 fev. 2016]. Disponível em: http:// www.mah.se/CAPP/Oral-Health-Promotion /WHO-Oral-Health-Fact-Sheet1/.

3. Patel RR, Tootla R, Inglehart MR. Does oral health affect self perceptions, parental ratings and video-based assessments of children's smiles? Community Dent Oral Epidemiol. 2007; 35(1):44-52.

4. Petersen PE. The World Oral Health Report 2003: continuous improvement of oral health in the 21st century - the approach of the WHO Global Oral Health Programme. Community Dent Oral Epidemiol. 2003; 31(1):3-24.

5. Suga USG, Terada RSS, Ubaldini ALM, Fujimaki M, Pascotto RC, et al. Factors that drive dentists towards or away from dental caries preventive measures: Systematic Review and Metasummary. PLoS ONE. 2014; 9(10). DOI: 10.1371/journal. pone.0107831.

6. Lima JPG, Uchida TH, Pavanello RM, Terada RSS, Pascotto RC, Pietrobon R, et al. Exploring factors influencing dental caries preventive measures by general dental practitioners in the public oral health care service in Paraná State. Rev ABENO. 2018; 18(2):72-84.

7. Milori AS, Nordi PP, Vertuan V, Carvalho J. Answers a preventive program dental plaque. Rev Odontol UNESP. 1994;
23(2):325-31.

8. Tomita NE, Pernambuco RA, Lauris JRP, Lopes ES. Educação em saúde bucal para adolescentes: uso de métodos participativos. Rev Fac Odontol Bauru. 2001; 9 (1/2):63-9.

9. Garcia PPNS, Campos FP, Rodrigues JA, Santos PA, Dovigo. Avaliação dos efeitos da educação e motivação sobre o conhecimento e comportamento de higiene bucal em adultos. Ciênc. Odontol Bras. 2004; 7(3):309.

10. Ferreira RI, Morano Jr. M, Meneghim MC, Pereira AC. Dental health education for adult patients: report of an experience. Rev Odontol UNESP. 2004; 33(3):149-56.

11. Silva JRA, Lemos EC, Hardman CM, Santos SJ, Antunes, MBC. Educação em saúde na Estratégia de Saúde da Família: Percepção dos profissionais. Rev Bras Prom Saúde. 2015; 28(1):75-81.

12. Tong A, Sainsbury P, Craig J. Consolidated criteria for reporting qualitative research (COREQ): a 32-item checklist for interviews and focus group. Int J Qual Health Care. 2007; 19(6):349-357.

13. Bardin L. Análise de Conteúdo. São Paulo: Edições 70, 2011.

14. Freire P. Pedagogia do oprimido. $43^{\mathrm{a}}$ ed. São Paulo: Paz e Terra; 1999.

15. Queluz DP. Cárie e conhecimento do flúor "na prevenção de escolares". Rev Gaúcha Odontol. 1995; 43(3):167-70.

16. Sinkoç C. Educação em Saúde Bucal e a motivação do paciente. Rev Odontol Universid Santo Amaro. 2001; 6(1/2):40-3.

17. Couto JL, Couto RS, Duarte CA. Motivação do paciente. Rev Gaúcha Odontol. 1992; 40:143-50.

18. Fonseca, EP. As Diretrizes Curriculares Nacionais e a formação do cirurgião-dentista brasileiro. J Manag Prim Health Care. 2012; 3(2):158-78. 
19. Saliba, CA, Saliba NA, Almeida AL, Freire M, Moimaz SAL. Estudo comparativo entre a eficácia da escovação orientada e supervisionada e a profilaxia profissional no controle da placa bacteriana dentária. Rev Odontol UNESP. 1998; 27(1): 185-92.

20. Moreira SG, Hahn MA. A importância dos hábitos de higiene bucal em programas que visam a promoção de saúde. Rev Gaúcha Odontol. 1994; 42:161-3.

21. Silva CMC, Meneghim MC, Pereira AC, Mialhe FL. Educação em saúde: uma reflexão histórica de suas práticas. Ciênc Saúde Colet. 2010; 15(5) 2539-50.

22. Kunert IR, Alves OP, Muller JO, Ott HA. Motivação em saúde bucal: programa "Saúde pela Boca". Rev Gaúcha Odontol. 1990; 38: 450-6.

23. Frazão, P. Custo-efetividade da escovação dental supervisionada convencional e modificada na prevenção da cárie em molares permanentes de crianças de 5 anos de idade. Cad Saúde Pública. 2012 28(2):281-90.

24. Pinto VG. Saúde bucal coletiva. $4^{\mathrm{a}}$ ed. Santos, São Paulo; 2000.

25. Cangussu MCT, Magnavita R, Rocha MCBS. Educação e construção da cidadania em um programa de saúde bucal em Salvador - Ba. Rev ABOPREV. 2001; 4(1):15-20.

26. Sheiham A. Public health approaches to promoting periodontal health. Rev Bras Odontol Saúde Coletiva. 2001; 2(2):61-82.

27. Santos PA, Rodrigues JÁ, Garcia PPNS. Conhecimento sobre prevenção de cárie e doença periodontal e comportamento de higiene bucal de professores de ensino fundamental. Ciênc Odontol Brasil. 2003; 6(1):67-74.

28. Martins BP, Uchida TH, Terada RSS, Pascotto RC, Fujimaki M. Análise
Qualitativa da percepção dos técnicos em saúde bucal sobre o desenvolvimento do papel do educador. Arch Health Invest. 2015; 4(5):28-35.

29. Cohen L, Dahlen G, Escobar A, Fejerskov O, Johnson NW, Manji F. La Cascada Declaration. DOI: 10.1111/adj.12546

30. Potter PA, Perry AG. Fundamentos de enfermagem. $5^{\mathrm{a}}$ ed. Rio de Janeiro: Guanabara Koogan; 2004.

31. Linard AG, Rodrigues MSP, Fernandes AFC. Comunicação na consulta ginecológica de enfermagem. Rev Tend Enferm Prof. 2009; 1(2):89-92.

32. Chiesa AM, Veríssimo MDLR. A educação em saúde na prática do PSF. Manual de enfermagem, 2001.

33. Moimaz SAS, Saliba NA, Saliba O, Almeida JCF. Educação para saúde bucal e prevenção. Avaliação entre cirurgiõesdentistas de serviço público e particular. Rev Gaúcha Odontol. 1994; 42(2):71-4.

34. Sousa LB, Aquino PS, Fernandes JFP, Vieira NFC, Barroso MGT. Educação, cultura e participação popular: abordagem no contexto da educação em saúde. Rev Enferm UERJ. 2008; 16(1):107-12.

35. Pauleto ARC et al. Saúde bucal: uma revisão crítica sobre programações educativas para escolares. Ciênc Saúde Colet. 2004; 9(1):121-30.

36. Santos KT, Pacheco F, Antonio C, Garbin CAS. Educação em saúde bucal na visão de acadêmicos de Odontologia. Arq Odontol. 2012; 48(2):96-101.

37. Guterman N. O cirurgião-dentista como educador em saúde bucal: explorações em torno de uma prática. Rev ABENO. 2005; 5(2):115-24.

38. Nunes TCM, Martins MICM, Sório RER. Proposições e estratégias de transformação dos recursos humanos em profissionais de 
saúde comprometidos com um sistema de saúde acessível, qualificado, sensível e humanizado. Cadernos da $11^{\text {a }}$ Conferência Nacional de Saúde, Brasília: Ministério da Saúde 2000; 313-31.

39. Brasil. Ato Portaria n.198/GM, de 13 de fevereiro de 2004. Institui a Política Nacional de Educação Permanente em Saúde como estratégia do Sistema Único de Saúde para a formação e o desenvolvimento de trabalhadores para o setor e dá outras providências. Brasília: Ministério da Saúde; 2004. p. 49.

40. Silva JAM, Ogata MN, Machado MLT. Capacitação dos trabalhadores de saúde na atenção básica: impactos e perspectivas. Rev Eletr Enferm 2007; 9(2):389-401.

41. L'Abbate S. Educação e serviços de saúde: avaliando a capacitação dos profissionais. Cad Saúde Pública. 1999; 15(2):15-27.

42. Pucci GCMF, Rech CR, Fermino RC, Reis RS. Associação entre atividade física e qualidade de vida em adultos. Rev Saúde Pública. 2012; 46(1):166-79

43. Stringheta PC, Oliveira TT, Gomes RC, Amaral MPH, Carvalho AF, Vilela MAP. Políticas de saúde e alegações de propriedade funcionais e de saúde para alimentos no Brasil. Rev Bras Ciênc Farm. 2007; 43(2):181-194.
44. Panzini RG, Rocha NS, Bandeira DR, Fleck MPA. Qualidade de vida e espiritualidade. Rev Psiq Clín. 2007; 34(supl1):105-115.

45. World Health Organization (WHO). A conceptual framework for action on the social determinants of Health. 2007. [Acesso em 19 out. 2017]. Disponível em: http:// www.who.int/social_determinants/resource s/csdh_framework_action_05_07.pdf.

46. Hayacibara MF, Lolli LF, Terada RSS, Hidalgo MM, Bispo CGC, Terada HH, Padilha LS, Rodrigues JK, Vicente AJ, Medeiros ACR, Calazans CM. Experiência de Clínica Ampliada em Odontologia na Universidade Estadual de Maringá. Rev Bras Educ Méd. 2012; 36 (1, Supl. 2):178183.

Correspondência para:

Mitsue Fujimaki

e-mail: mfujimaki@uem.br

Departamento de Odontologia

Universidade Estadual de Maringá

Av. Mandacaru, 1.550

87080-000 Maringá/PR 